\title{
Psychological Resilience and Occupational Injuries
}

\author{
Simo Salminen1, Pia Perttula², Vuokko Puro² \\ ${ }^{1}$ University of Helsinki, Helsinki, Finland \\ ${ }^{2}$ Finnish Institute of Occupational Health, Helsinki, Finland \\ Email: simo.salminen@pp.inet.fi
}

How to cite this paper: Salminen, S. Perttula, P., \& Puro, V. (2020). Psychological Resilience and Occupational Injuries. Psychology, 11, 461-466.

https://doi.org/10.4236/psych.2020.113031

Received: October 9, 2019

Accepted: March 22, 2020

Published: March 25, 2020

Copyright (c) 2020 by author(s) and Scientific Research Publishing Inc. This work is licensed under the Creative Commons Attribution International License (CC BY 4.0).

http://creativecommons.org/licenses/by/4.0/

\begin{abstract}
Resilience embodies the personal qualities that enable one to thrive in the face of adversity. A previous Italian study showed that injured workers had a lower level of resilience than non-injured workers. The aim of this paper is to examine the relationship between occupational injuries and psychological resilience. The subjects consisted of 197 drivers from two Finnish waste transport companies. As part of a larger questionnaire, they filled in the Connor-Davidson Resilience Scale, which had 25 items. The drivers reported their occupational injuries during the last three years. The drivers with occupational injuries had a higher score (average 69.3) on the Connor-Davidson Resilience Scale than the drivers without injuries (67.7). According to Student's t-test, the difference between the groups was highly significant $(\mathrm{t}=40.44, \mathrm{df}=196, p<0.001)$. The result of this study was contradictory to the earlier Italian study. One explanation may be that the Italian study had been done in a traumatic context with seriously injured patients. The waste transport drivers were rather young and fit males, who had suffered only minor injuries.
\end{abstract}

\section{Keywords}

Work Accidents, Drivers, Waste, Finland

\section{Introduction}

In the Oxford Dictionary of English, resilience is defined as being "able to withstand or recover quickly from different conditions" (Soanes \& Stevenson, 2006). The roots of the construct of resilience are both in the psychological aspects of coping and the physiological aspects of stress (Tusaie \& Dyer, 2004). Psychological resilience is then conceptualized as "the interactive influence of psychological characteristics within the context of the stress process" (Fletcher \& Sarkar, 2013). 
Thus, a person is potentially resilient before an adversity while it is in the crisis situation his/her reactions and resilience are actually to be seen.

There are several measures of psychological resilience. Perhaps the most often used is the Connor-Davidson Resilience Scale (CD-RISC), which has 25 items. The scale has a satisfactory internal consistency, test-retest reliability and convergent validity, and it has five factors (Connor \& Davidson, 2003). The construct validity of the Connor-Davidson Scale has also been confirmed (Campbell-Sills, Cohan, \& Stein, 2006). Burns and Anstey (2010) found support for the one-factor model they used instead of the five-factor model of the original scale. Later Campbell-Sills and Stein (2007) found a 10-item unidimensional scale to be better than the original scale, a result which has been confirmed among Australian cricketers (Gucciardi, Jackson, Coulter, \& Mallett, 2011). Even the scale with two items has been found to have a good test-retest reliability, convergent validity and divergent validity (Vaishnavi, Connor, \& Davidson, 2007).

The association between psychological resilience and occupational injuries has only been examined in one study. Ghisi and her co-workers (2013) showed that injured Italian workers had a lower level of resilience measured by the Connor-Davidson Resilience Scale than non-injured workers. The injured workers were seriously hurt and resilience was associated with other psychological measures (Beck Depression Inventory, State-trait Anxiety Inventory and PTSD Symptom Scale). The aim of this paper is to examine the relationship between psychological resilience and occupational injuries with a data set of healthy workers. In addition, we tested the five-factor structure of the Connor-Davidson Resilience Scale to test the original five-factor model.

An occupational injury is defined as an unexpected and unintentional series of events leading to a physical harm to a person at work. Men usually get injured more often than women. Young and old workers get injured more often than middle-aged ones. Inexperienced employees have an elevated risk of injury especially during their first month at the workplace (Salminen, 1994).

\section{Materials and Methods}

In Finland, waste transport drivers mostly drive alone. During one work shift, they empty around 100 to 300 waste containers. The injury rates of waste transport drivers were three times higher than the average rates of industry (Ettala, Rahkonen, \& Peltola, 1989). In addition to mixed waste collection, biological waste, glass and metal waste, paper and carton waste are collected separately.

The participants were 197 drivers from two Finnish waste transport companies. All of them were males. Most of the drivers were middle-aged (26 - 50 years, 66\%), whereas $22 \%$ were under 26 years of age and $12 \%$ over 50 years of age. Thirty-nine of the drivers had been in the company under one year, 59 had worked 1 - 4 years and 36 longer time. All subjects gave their informed consent for inclusion before they participated in this study. This study was conducted in accordance with the Declaration of Helsinki, and the protocol was approved by the Ethics Committee of Finnish Institute of Occupational Health (ETR 5/2014). 
As part of a larger questionnaire, psychological resilience was measured by the Connor-Davidson Resilience Scale (CD-RISC), which had 25 items. The longest version of CD-RISC was selected, because it is the original one and the most studied (Connor \& Davidson, 2003). The instruction said that the CD-RISC is a part of an American questionnaire measuring individuals' possibilities to survive in challenging situations. The rating was not restricted to the work life. Cronbach's alpha coefficient, measuring the internal consistence of the scale, was 0.90 . We used the official Finnish translation made in the University of Jyväskylä. It is a back translated version of the scale. In addition, the participants were asked to report their occupational injuries from the last three years. Forty-nine drivers had been involved in injuries, whereas 148 had avoided injuries. The defining as an occupational injury is based on the drivers' self-reporting: "Have you had any injury related to this work task during the last three years?" All kinds of injuries (minor-serious) are included in this study, because the number of injuries is not very high.

Means and Student's t-test was used to analyze the difference in the resilience score between the injury-involved and injury-free groups. In the factor analysis of the research sample, we used an exploratory principal components analysis with a varimax rotation in order to test the original five-factor model. This type of factor analysis was used also in the original study. We used SAS 9.0 in the analyses.

\section{Results}

The drivers with occupational injuries had a higher CD-RISC score (average 69.3 points) than the drivers without injuries (67.7). Although according to Student's $\mathrm{t}$-test the difference between them was highly significant $(\mathrm{t}=40.44, \mathrm{df}=196, p<$ $0.001)$, the effect size was rather small $(\mathrm{d}=0.37)$ and the two points' difference is not clinically meaningful. Demographic factors (age and tenure) were not related to occupational injury.

In the factor analysis, the model of five factors was the most suitable for the data. We named the first factor as Facing the challenges. Factor 2 was called Belief in myself. Factor 3 was named Social support in the face of stress. Factor 4 was related to Self-confidence. Factor 5 could be called as Deterministic. The factor pattern for the scale is presented in Table 1 . The eigenvalues of the five factors were $7.07,1.11,0.96,0.73$ and 0.56 , respectively.

\section{Discussion}

The internal consistency of the scale in this study was 0.90 , which is on the same level as that of the original study (Connor \& Davidson, 2003). Then the Finnish version of the scale is a reliable tool for assessing psychological resilience. However, our study design did not allow to examine the validity of the scale.

This study showed that the drivers with injuries had a higher score on the resilience scale than the drivers without injuries. This result was contradictory to the earlier Italian study, which found a lower resilience score among injured people (Ghisi et al., 2013). One explanation may be that the participants of the 
Table 1. Varimax-rotation of five factor solution of CD-RISC.

\begin{tabular}{|c|c|c|c|c|c|}
\hline \multicolumn{6}{|c|}{ Factors (Eigenvalues) } \\
\hline Item & $1(7.072)$ & $2(1.114)$ & $3(0.956)$ & $4(0.727)$ & $5(0.556)$ \\
\hline 17 & 0.72829 & 0.28677 & 0.01846 & 0.26116 & 0.13043 \\
\hline 23 & 0.71038 & 0.12644 & 0.08323 & 0.09933 & -0.00469 \\
\hline 25 & 0.61825 & 0.15815 & 0.19001 & 0.08544 & 0.23276 \\
\hline 14 & 0.60714 & 0.24568 & 0.18098 & 0.19294 & 0.01010 \\
\hline 22 & 0.59375 & 0.07148 & 0.29559 & 0.03893 & 0.11948 \\
\hline 19 & 0.57464 & 0.09628 & 0.24488 & 0.36109 & -0.03772 \\
\hline 16 & 0.55627 & 0.38998 & 0.13065 & 0.20934 & 0.14730 \\
\hline 24 & 0.51444 & 0.34514 & 0.06881 & 0.17531 & 0.05931 \\
\hline 21 & 0.44885 & 0.03176 & -0.0553 & 0.15138 & 0.32297 \\
\hline 15 & 0.33667 & 0.24726 & 0.11905 & 0.15871 & 0.15498 \\
\hline 12 & 0.17531 & 0.56356 & 0.25231 & -0.08627 & 0.28831 \\
\hline 5 & 0.24198 & 0.54488 & 0.16434 & 0.15385 & 0.04797 \\
\hline 11 & 0.30528 & 0.51138 & 0.26345 & 0.02448 & 0.36049 \\
\hline 4 & 0.12103 & 0.48353 & -0.03153 & 0.36841 & 0.08058 \\
\hline 6 & 0.11267 & 0.45367 & 0.12467 & 0.35067 & 0.10130 \\
\hline 1 & 0.26472 & 0.44608 & 0.38465 & 0.00606 & -0.16052 \\
\hline 2 & 0.03249 & 0.13260 & 0.57401 & 0.02857 & -0.01094 \\
\hline 13 & 0.25334 & 0.06548 & 0.52811 & 0.14341 & 0.13688 \\
\hline 8 & 0.18115 & 0.28288 & 0.44310 & 0.13270 & 0.13180 \\
\hline 20 & 0.18807 & 0.13001 & 0.07831 & 0.51036 & 0.17101 \\
\hline 18 & 0.20902 & 0.01287 & 0.07575 & 0.45910 & 0.02987 \\
\hline 7 & 0.17079 & 0.32930 & 0.11777 & 0.43963 & 0.11071 \\
\hline 9 & 0.09507 & 0.12024 & 0.10552 & 0.10760 & 0.50259 \\
\hline 10 & 0.35988 & 0.15652 & 0.28415 & -0.04668 & 0.44579 \\
\hline 3 & -0.00795 & 0.04193 & -0.10240 & 0.26563 & 0.35220 \\
\hline
\end{tabular}

The whole names of 25 items: 1 . Able to adapt to change; 2 . Close and secure relationships; 3 . Sometimes fate or God can help; 4. Can deal with whatever comes; 5 . Past success gives confidence for new challenge; 6. See the humorous side of things; 7. Coping with stress strengthens; 8 . Tend to bounce back after illness or hardship; 9. Things happen for a reason; 10. Best effort no matter what; 11. You can achieve your goals; 12. When things look hopeless, I don't give up; 13. Know where to turn for help; 14. Under pressure, focus and think clearly; 15 . Prefer to take the lead in problem solving; 16 . Not easily discouraged by failure; 17. Think of self as a strong person; 18. Make unpopular or difficult decisions; 19. Can handle unpleasant feelings; 20. Have to act on a hunch; 21 . Strong sense of purpose; 22. In control of your life; 23. I like challenges; 24 . You work to attain your goals; 25 . Pride in your achievements.

Italian study were seriously injured patients, whereas the waste transport drivers in this study were rather young and fit males, who had suffered only minor injuries. 
It is possible that injury-involved drivers recognized the risks of their job better and they are in this way more resilient than drivers who had avoided injuries. The Italian study did not report which kind of injuries the subjects had been involved and from which industries they were. Another possible explanation is that resilient drivers can better find new solutions to problematic situations. In these situations, they may violate safety orders and this can result in injuries. Hollnagel (2007) assumed from the resilience perspective that variability in the performance of employee may cause injuries.

Although the five-factor model fits both the original data (Connor \& Davidson, 2003) and these data, the single items were loaded to different factors. All three items in our fourth factor were from the original second factor. Two out of the three items in our third factor were the same as in the original third factor and two out of the three items in our fifth factor were the same as in the fifth original factor. Our first and second factors were more a mixture of different original factors. We can conclude that although the factor patterns were the same, our study did not perfectly repeat the original study. One explanation for this result is that the meaning of words is different in the U.S. and in Finland as we later discussed.

The Connor-Davidson Resilience Scale has been criticized for that the five subscales may be correlated with each other. The scale may not consist of five distinct subscales (White, Driver, \& Warren, 2008). Because the scale was developed by American psychiatrics, some items were rather strange for Finnish employees. For example, the item 3 "Sometimes fate or God can help" seems weird in a secular country like Finland. In future, we recommend using a scale that concentrates on work issues if the subjects of the study consist of employees.

The results of this study showed that psychological resilience is relevant in the work of waste transport drivers. They encounter unexpected events during their working day and must find out creative solutions to these problems. A resilient character helps a driver to react more sensitively to the weak signals of possible problems at work. The situation is the same in many other occupations, which shows the significance of psychological resilience in the work life.

\section{Conclusion}

This study showed that the waste transport drivers with occupational injuries had a higher resilience score than the drivers without injuries. This result, obtained with healthy workers, was contradictory to the previous Italian study with seriously injured patients.

\section{Conflicts of Interest}

The authors declare no conflicts of interest regarding the publication of this paper.

\section{Acknowledgements}

The European Research Fund Saf€ra and the Finnish Work Environment Fund have supported this study. 


\section{References}

Burns, R. A., \& Anstey, K. J. (2010). The Connor-Davidson Resilience Scale (CD-RISC): Testing the Invariance of a Uni-Dimensional Resilience Measure that Is Independent of Positive and Negative Affect. Personality and Individual Differences, 48, 527-531. https://doi.org/10.1016/j.paid.2009.11.026

Campbell-Sills, L., \& Stein, M. B. (2007). Psychometric Analysis and Refinement of the Connor-Davidson Resilience Scale (CD-RISC): Validation of a 10-Item Measure of Resilience. Journal of Traumatic Stress, 20, 1019-1028. https://doi.org/10.1002/jts.20271

Campbell-Sills, L., Cohan, S. L., \& Stein, M. B. (2006). Relationship of Resilience to Personality, Coping, and Psychiatric Symptoms in Young Adults. Behavioral Research \& Therapy, 44, 585-599. https://doi.org/10.1016/j.brat.2005.05.001

Connor, K. M., \& Davidson, J. R. T. (2003). Development of a New Resilience Scale: The Connor-Davidson Resilience Scale (CD-RISC). Depression \& Anxiety, 18, 76-82. https://doi.org/10.1002/da.10113

Ettala, M., Rahkonen, P., \& Peltola, H. (1989). Work Safety in Waste Collection and Transport. Waste Management \& Research, 7, 241-248. https://doi.org/10.1177/0734242X8900700131

Fletcher, D., \& Sarkar, M. (2013). Psychological Resilience. A Review and Critique of Definitions, Concepts, and Theory. European Psychologist, 18, 12-23. https://doi.org/10.1027/1016-9040/a000124

Ghisi, M., Novara, C., Buodo, G., Kimble, M. O., Scozzari, S., Di Natale, A., Sanavio, E., \& Palomba, D. (2013). Psychological Distress and Post-Traumatic Symptoms Following Occupational Accidents. Behavioral Science, 3, 587-600.

https://doi.org/10.3390/bs3040587

Gucciardi, D. F., Jackson, B., Coulter, T. J., \& Mallett, C. J. (2011). The Connor-Davidson Resilience Scale (CD-RISC): Dimensionality and Age-Related Measurement Invariance with Australian Cricketers. Psychology of Sport and Exercise, 12, 423-433.

https://doi.org/10.1016/j.psychsport.2011.02.005

Hollnagel, E. (2007). Human Factors \& Safety Today. Paper Presented at the Seminar "Human factors \& Safety II-Human Factors and Safety". Espoo, Finland: VTT, 12.4.

Salminen, S. T. (1994). Epidemiological Analysis of Serious Occupational Accidents in Southern Finland. Scandinavian Journal of Social Medicine, 22, 225-227. https://doi.org/10.1177/140349489402200312

Soanes, C., \& Stevenson, A. (2006). Oxford Dictionary of English (2nd ed.). Oxford, UK: Oxford University Press.

Tusaie, K., \& Dyer, J. (2004). Resilience: A Historical Review of the Construct. Holistic Nursing Practice, 18, 3-10. https://doi.org/10.1097/00004650-200401000-00002

Vaishnavi, S., Connor, K., \& Davidson, J. R. T. (2007). An Abbreviated Version of the Connor-Davidson Resilience Scale (CD-RISC), the CD-RISC2: Psychometric Properties and Applications in Psychopharmacological Trials. Psychiatry Research, 152, 293-297. https://doi.org/10.1016/j.psychres.2007.01.006

White, B., Driver, S., \& Warren, A.-M. (2008). Considering Resilience in the Rehabilitation of People with Traumatic Disabilities. Rehabilitation Psychology, 53, 9-17. https://doi.org/10.1037/0090-5550.53.1.9 